\title{
Drug Misuse among High Schoolcandidates in Mutare Urban and Peri Manicaland Province, Zimbabwe
}

\author{
Patricia Muchena ${ }^{1}$, Janet Makotamo ${ }^{2}$ \\ ${ }^{I}$ Faculty of Science and Technology, Zimbabwe Open University, Manicaland Region P. Bag V7480, Mutare. \\ Zimbabwe. \\ ${ }^{2}$ Faculty of Science and Technology, Zimbabwe Open University, Manicaland Region P. Bag V7480, Mutare, \\ Zimbabwe
}

\begin{abstract}
Several researches on drugs show that a number of drugs are misused by people of different age groups. Students around the world including candidates are not left out of this mess. Drugs have several risks to human health and the environment. The focus of this survey was drug misuse by high school candidates in Manicaland Zimbabwe during 2015. The study aims at determining the drugs misusedroute of administration and frequency of takingby high school candidates in Manicaland, Zimbabwe. The respondents in this study were extracted from a population of 354 candidates from three boarding high schools (a government boys boarding, girls boarding high schools and a private co-educational boarding high school in Mutare). The sample was composed of eighty-eight candidates randomly selected. A questionnaire was used for data collection. The results of the study revealed dragon, red bull, coffee, marijuana, bio-plus, bronco, glue, all other energy drinks, monster among others as the main misused drugs during examination periods. The conclusion made was that drug misuse is prevalent amonghigh school candidates in Mutare urban and peri, in Manicaland, Zimbabwe. Candidates misuse drugs to enhance brain alertness during examination time. Both boys and girls in both government and church -run boarding high schools take drugs even the controlled ones at the same rate.This study recommends that school sensitize students on drug misuse/abuse and the effects of drugs on health and the environment in the schools. Education on drugs should be taken seriously.
\end{abstract}

Key words: Drugs, misuse, abused, high school candidates

\section{Background Of The Study}

Drug Abuse is a public concern in all age groups and sectors .Much has been written about it worldwide by scholars such as, Frischer, Crome \& Macleod, (2005); Frischer, Rehm, Brissette \& Brochu, (2005);Kuria, (1996) ; Kasuja,2016; Roe \& Martin,(2006);Volkow and Li (2005); Walter, 2006 and Wilson ,Compton, Nora and Volkow,(2006); . The mentioned authors have written about drug abuse in different areas especially schools, workplace, colleges and universities. Drug abuse has been conceptualised in many ways as said below. The World Health Organisation, WHO (1969) defines drug abuse as the persistent or sporadic excessive drug use inconsistent with or unrelated to acceptable medical practice. Drug Abuse can also be called drug misuse, maltreatment or excessive use of the drugs (Thesaurus Dictionary, 2013). Drug abuse/misuse is defined as habitual use of drugs not needed for therapeutic purposes, solely to alter ones mood, or affect state of consciousness (Fartex, Partner Medical Dictionary, 2012; The American Heritage Medical Dictionary, 2007). The University of Maryland Medical Centre concurs with the above definitions that drug abuse is the recurrent use of illegal drugs or the misuse of prescriptions or over the counter drugs with negative consequences. These consequences may involve problems at work, school, and home or in interpersonal relationships. Drug misuse can also be known as the disease model of drug misuse (Volkow\& Li, 2005). In this study drug abuse, drug misuse or substance abuse will be used interchangeably.

The prevalence of injecting drug users in London is 4, 2\% (Judd, Hickman, Jones,(2005).In the United Kingdom (U K), it has been estimated that around 4 million people use illicit drugs each year with Cannabis being the most commonly used followed by Cocaine and Ecstasy. Opiods misuse occurs on a smaller scale but is associated with much greater rates of harm (Roe \& Man, 2006).Stimulants are also abused. Stimulants refer to any substance that activates, enhances or increase neural activity (WHO, 2006). Roe \& Man (2006) states that Cocaine is one of the most commonly misused illicit stimulants in the UK. According to Campton \& Volkow, (2006) some of the commonly abused drugs are Alcohol, Nicotine, Marijuana, Barbiturates, Cocaine, Methaqualone, Opium, Alkaloids, Synthetic Opiods, Benzodiazepines, Ketamine anabolic substances.Ward, Henderson, Pearson, (2003) concerning UK psychosocial treatment of the misuse of Opiods, stimulants and cannabis found that drug misuse is more common in certain vulnerable groups that is the school leavers aged between 14 and 24 years. The 11 to 17 years age group has the majority of young people found misusing cannabis primarily (2003) Widespread abuse of drugs is also reported in the United States of America. Several categories of prescription drugs have increased markedly in the past decade and are now at alarming levels for 
certain agents especially Opiods, Analgesics and Stimulants. This means Prescription drugs fit into the same pharmacological classes as there non-prescription drugs (Wilson, Compton, Nora \&Volkow, 2006). This might reflect the easily availability and accessibility of drugs. The level of drug misuse is paramount in the age group 15 to 24 years. Anthony, Warmer, \&Kessler (1994) states that Cocaine is mostly initiated at the age of 20 years and the risk of dependence occurs early after first use and persists for approximately 10 years. Likewise cannabis use is started in early adolescence with the heaviest use in the 15 to 24 years age group (Harkin, Anderson \& Goos, 1997). This may be as a result of strong peer influences (Frischer, Rehm, Brissette and Brochu, 2005). According to the National British Crime Survey 2005/6 as cited by Roe \& Man, (2006), statistics show that $34.9 \%$ of $16-59$ years old had used one or more illicit drugs in their life time, $10.5 \%$ in the previous year and $6.3 \%$ in the previous month. In the same survey, Frischer et al., (2001) estimated that 226000 $(0.5 \%)$ of Britain's population were problem drug users and males comprised over $70 \%$.Statistics, (2006) found that young people who had used drugs in the past year were over twice as likely to have committed an offence compared with those who reported not having used drugs (52\% versus 19\%). According to the 2012 Monitoring the Future Survey, which tracks drug use among American adolescents and young adults illicit drug use is more common among males in high school and college and among high school seniors $9 \%$ of males use marijuana daily whilst less than, $4 \%$ females use it daily but, the case is different with younger teens girls who tend to abuse drugs at the same rate as boys. Walter, (2004) on the National Survey on Drug Use and Health indicated that girls surpass boys in abusing prescription drugs. Of the youths surveyed in $200414.4 \%$ of girls and $12.5 \%$ boys were reported misusing prescription drugs Across the world considerable work has been done in studying drug misuse among adolescents. WHO, (2009) had a meeting of drug monitoring which lies on non-medical drug use related to substance abuse. The different drug categories used are heroin, Opiates, Amphetamine type Stimulants, Cocaine and Cannabis. The American National Institute on Drug Abuse came up with Drug Facts on High School and Youth Trends (2005). The facts were on the American $8^{\text {th }}, 10^{\text {th }}$ and $12^{\text {th }}$ graders who showed a high rate of e-cigarette smoking. Top drugs among the $8^{\text {th }}$ and $12^{\text {th }}$ graders were as follows.

Table 1: Top drugs among the $8^{\text {th }}$ and $12^{\text {th }}$ graders in America

\begin{tabular}{|l|l|l|l|}
\hline \multicolumn{2}{|l|}{$8^{\mathrm{TH}}$ Graders } & Percentage & $12^{\text {th }}$ Graders \\
\hline Drug & $11 \%$ & Drug & Percentage \\
\hline Marijuana & Marijuana & $15.1 \%$ \\
\hline Inhalants & $5.3 \%$ & Adderal & $6.8 \%$ \\
\hline Synthetic marijuana & $3.3 \%$ & Synthetic marijuana & $5.8 \%$ \\
\hline Cough medicines & $2.0 \%$ & Vicodine & $4.8 \%$ \\
\hline Tranquilisers & $1.7 \%$ & Tranquilisers & $4.7 \%$ \\
\hline Adderal & $1.3 \%$ & Cough medicines & $4.1 \%$ \\
\hline Halucinogens & $1.3 \%$ & Sedatives & $4.3 \%$ \\
\hline Oxycontin & $1.0 \%$ & Hallunogens & $4.0 \%$ \\
\hline Vicodin & $1.0 \%$ & Ectacy & $3.6 \%$ \\
\hline Any form Cocaine & $1.0 \%$ & Oxycontin & $3.3 \%$ \\
\hline Ectacy & $0.9 \%$ & Cocaine (any form) & $20 \%$ \\
\hline Gitalin & $0.9 \%$ & Inhalants & $1.9 \%$ \\
\hline & & Salvis & $1.8 \%$ \\
\hline & & Gitalin & $1.8 \%$ \\
\hline
\end{tabular}

Source: The American National Institute on Drug Abuse came up with Drug Facts on High School and Youth Trends (2005).

In a survey done in Nigeria the prevalence and pattern of drug abuse among Part 1 Medical Students at a Nigerian University was $81 \%$ male drug abusers $19 \%$ females and the mostly commonly abused substances were alcohol $60 \%$, minor tranquilizers $48 \%$, tobacco $35 \%$, narcotics $29 \%$ mainly codeine and $11 \%$ abused cannabis. In another study at the same university most students were poly drug abusers and drug abuse was most prevalent among the fourth and the final year students. Seven hundred and twenty eight out of seven hundred and seventy five medical students were surveyed. The abuse of drugs is rapidly going up even though the history is relatively short.

Drug abuse has become part of life for schools in Uganda today. Many students start abusing drugs as early as 11 years and by the age of 25 eight in 10 students say that they have ever taken drugs such as alcohol, kuber cigarettes, shisha, marijuana and khart. The statistics of the survey done show that alcohol tops the list of drugs abuse with 77.7 per cent, followed by Kuber at (34\%), cigarettes at (29.5\%), shisha (21.4\%), marijuana (17.9\%), Kaht (17\%), murah (8.0\%) and cocaine (6.3\%) (Kasujja, 2016)

According to Kasujja (2016) research results the percentage of students drug use is significantly higher in boarding schools $25 \%$ as compared to day schools at $15 \%$. More so the percentage of students taking drugs is higher in private schools at $31 \%$ compared to Government schools. Zickier, (2000) NIDA NOTES Staff Writer concluded that Males are more likely than females to abuse drugs. The just said point was opposed by (James Anthony, a NIDA supported scientist at the Johns Hopkins University school of gender difference in rates of 
Drug misuse among High Schoolcandidates in Mutare urban and peri Manicaland Province,

drug abuse who states that there is no difference with respect of trying a drug once an opportunity to do so has been experienced. In a comparative study by Kuria (1996)in Kenya, on Drug abuse among Urban versus Rural secondary schools it was found that more male students abused drugs more often than female students. Alcohol emerged as the most commonly abused drug (15\% and $14 \%$ in urban and rural schools respectively).

The SADC Region has not been spared from drug abuse and drug trafficking. The SADC Region is made up of 14 member states with a combined population of 200 million people. In the1997 SADC Drug Control Database key findings were that alcohol is the most abused drug that causes the most problems seconded by cannabis/ marijuana/mbanje most damaging. Zimbabwe has more than 2158 hectares of land which is used for cannabis cultivation. Heroin is a serious problem in Mauritius, Botswana, Swaziland, Tanzania, and Zambia whilst Namibia, Zambia and Zimbabwe reported an increase in Opiate abuse among all age groups. Methaqualone (Mandrax) is a problem for Namibia and South Africa and 29 drug control projects are being implemented. Rudatsika, Maposa, Mukandavire, Muula and Siziva, (2009) conducted a study on the Prevalence and predictors of illicit drug use among school-going adolescents in Harare Zimbabwe. There were 1984 adolescent participants in the study of which $50.7 \%$ were females; 15 years olds were $30.3 \%$ non- smokers and non- alcoholic drinkers. Nine per cent of the subjects (13.4 males and $4.9 \%$ females) reported having used marijuana or glue. The results showed that marijuana or glue use was positively associated with cigarette smoking, alcohol drinking and sexual intercourse and males were more likely to have used marijuana or glue than females.

According to a Zimbabwean Herald Article on the $6^{\text {th }}$ of February 2014 a teenage Joshua Merrick 19 years old died in his sleep after taking a tin of high-caffeine energy drink called Animal Rage to boost his work-outs stated that the caffeine energy drink is popular among children and teenagers. Some tins of high energy drinks contain 13 teaspoons of sugar and two cups of coffee. These drinks are accessible to anyone as they are sold over the counter just like any ordinary drink. Dr Jack James once commented in a paper that all energy drinks need to be controlled just like alcohol and cigarettes. The caffeine content drinks include coffee, energy drinks, soda, tea and shots.

Statistics from the Anti-Drug Abuse Association of Zimbabwe as reported by Tatenda Gapa on $19^{\text {th }}$ March 2015 show that school children are being admitted to medical institutions suffering from mental problems related to drug abuse and this has reached alarming levels in Zimbabwe. The mostly abused drugs include cannabis (marijuana), Broncleer commonly known as "bronco". The later drug is a bronchodilator which contains codeine and alcohol. This is a cause of concern, more than 100 cases of drug and alcohol abuse are reported monthly only in Harare and this involves both boys and girls. Senior Assistant Commissioner Charity Charamba, (2015) said that some girls in Mutare had been detained for possessing illegal drugs and seven other school girls from Dangamvura were caught in possession of illegal drugs and arrested. These reports imply that drug abuse is in existence in high schools. Therefore these reports motivated the researchers to do a study on Drug Abuse among High school boarding candidates in Mutare urban and peri urban. This study seeks to find out the extent of drug misuse among high school boarding candidates in Mutare urban and peri urban Manicaland.

In a study in England by Gossop,Marsden, Stewart, \& Treacy,(2000) reported that routes of drug administration included injecting,smoking, snorting and oral.For some drugs such as methadone and benzodiazepines one main route of administration was the injection. For other drugs (heroine, amphetamines and cocaine powder, there were marked variations in route. Heroine injectors were more likely also to use other drugs by injection.

\section{Statement of the problem}

Statistics report from Anti-Drug Abuse Association of Zimbabwe on 19 March, 2015 reported that high school children are being admitted to medical institutions suffering from mental problems related to drug abuse in Zimbabwe. The Zimbabwean police Senior Assistant Commissioner Charity Charamba,(2015) also reported that school girls in Mutare urban /Dangamvura were caught in possession of illegal drugs and were arrested.These reports motivated the researchers to find out thee extend of drug misuse among high school boardingcandidates in Mutare urban and Peri urban, Manicaland Province.

\section{Purpose of the study}

The purpose of the study is to determine the drugs misused, route of administration and frequency of taking, by High school candidates in Mutare Urban and Peri urban Manicaland Province, Zimbabwe

\section{Research questions}

The study intended to answer the following questions:

1. Which drugs are misused by high school candidates in Mutare Urban and Peri urban Manicaland Province?

2. How are the high school candidates taking the drugs? 
3. What is the high school candidates' frequency of taking drugs in Mutare urban and Peri urban Manicaland Province?

4. How are the high school candidates views on drug misuse associated focusing on type of school and gender.

\section{Theoretical framework}

Bandura, Stajkovic, and Luthans, (1998) Social Cognitive Theory and self- efficacy: Implications for Motivation Theory and Practice was used to guide this research. Social Cognitive Theory is a theory of human behaviour which is made up of the following concepts the person, the environment and the behaviour.

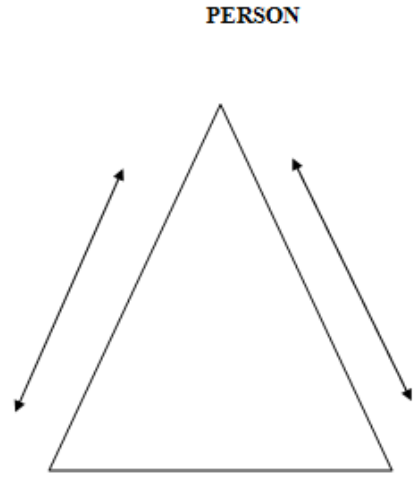

ENVIRONMENT

BEHAVIOUR

BANDURA SOCIAL COGNITIVE THEORY

Person

People process and act upon available information differently depending on their personal characteristics, that means the ability to control self. The students' self-efficacy, self- control and self- status make an important contribution towards ones behaviour depending on their belief. For example if one gets drunk and colleagues cheer him/her up for having a non- functioning mind(stick mind) as after tacking marijuana he/she may become motivated to continue misusing the drug.

\section{Environment}

The environment in which the student was brought up and the school environment he/she is learning plays a significant role in shaping the social and behavioural aspect of the student. The student might have been brought up by the parents who are drug addicts and on top of that starts mixing with drug abusers at the high school where he/she is learning. The environment can therefore be very influential to the individual's drug abusing behaviour.

\section{Behaviour}

The individuals' behaviour is therefore shaped by the upbringing and beliefs, environmental practices and the individuals self- efficacy. One may decide not to engage in drug abusing practices depending on his/her selfefficacy. The behaviour of the student may be reflected by abusing drugs or not abusing the drugs and the end results behaviour portrayed after abusing the drugs.

\section{Research design}

\section{Methodology}

The study was a survey. A survey was used because it captures perceptions, views and behaviours of participants on the misuse of drugs. This design was effective in the sense that it enabled the researchers to collect information, describe it and explain the candidates' ideas, beliefs, feelings and experiences on the misuse of drugs as individuals without peer influence.

\section{Population and setting:}

The high school candidates are candidates learning at boarding schools in Mutare urban and peri urban, Manicaland Province. One high school under study is a church-run co-educationalboarding school while the others two are single sex government boarding high school.The candidates were preparing to write the 
November 2015 national examinations. The candidatesknow that the national examinations are crucial in their lives. The examinations form a basis for their future profession, skill development or entry to university programme. The terms student and candidate will be used interchangeably in this study. Three hundred and fifty-four (354)high school candidates from the 3 boarding schools in Manicaland comprised the population in this study. This population consisted of 119 and 96 O-level (215) and 72 and 67 (139) A-level boys and girls respectively. This gives a total of 191 boys and 163 girls.

\section{Sample and sampling procedure}

Of the Three hundred and fifty-four possible participants for this studya quarter of the population was an ideal number for generalization of the results. The researchers used stratified and simple random sampling methods. The researchers approached the head at each research site and informed the head on the purpose of the study. The heads assembled the "O" and "A" level candidates and researcherswhere given the floor to explain the purpose of the study and that participation was voluntary, anonymity and confidentiality of information was to be observed. The researchers used the school class registers to do stratified random selection of the respondents. The study stators where boarding schools in Mutare urban and peri respondents, O level and A level students and boys and girls. To select the boys and girls respondents the study used simple random sampling on every fourth name in the register list per form per school. This sample included 54 (61\%) O-Level and 34 (39\%) A-Level candidates. The selected boys and girls were taken to a separate room where they were given questionnaire to respond to.

\section{Instrumentation}

A7-item self administered questionnaire was used. The questionnaire was divided into two sections. The first section solicited the bio-data age, level of study at high school and the second part sought data on whether the candidate had ever used any substance to stimulate their brain during examination period. If they did, the questionnaire then sought the type of substance and the route they used for each.The questionnaire was used because of the large number of respondents to be surveyed. It was the most appropriate instrument where respondents in the study could be surveyed at the sometime at each research site. It was also very cost effective and economical in the use of time (Munn and Drever 1999). The 7closed- ended questionswere used in order to solicit specific responses about the candidate. Responses from closed - ended questions were easy to tabulate and more items were allowed than would open-ended questions (Tichapondwa, 2013, p.126).

\section{Instrument development}

The questions for the survey were crafted in linewith the research questions for the study. The two researchers independently drafted a number of questions as they could for each research question. Then the two researchers met, discussed and reached consensus on what questions were suitable to include in the questionnaire. They made sure that the questions solicited all the information that was required in the study. The researchers after consultations with colleagues, known to be well-versed in this type of research, agreed that the instrument be pilot tested.

\section{Pilot study:}

To make sure that the questionnaire would collect the data that was needed without presenting any difficulties to the respondents, the questionnaire was pilot tested with twenty high school candidates from a government co-educational day school in Mutare urban. Participants in the pilot study were not part of the main study. Afterthe pilot testing no major modifications to the questionnaire were made.

\section{Data collection procedure}

The lead researcher sought permission from the Ministry of Primary and Secondary Education to carry out the study. The researchers then visited the schools and asked the heads at each boarding high school to allow them to address the ' $\mathrm{O}$ ' and ' $\mathrm{A}$ ' level candidates on the topic of the study. The researchers informed the candidates that those who were willing to participate would answer a self-administered questionnaire in a separate room. The prospective respondents were informed that the information they would give would be held in confidence and would not be used for purposes beyond the study. They were also informed that only the researchers would have access to the completed questionnaires. Identities of the respondents who had to complete the questionnaires were not to be exposed to anyone else except the researchers. The prospective respondents were informed further that taking part in the study was entirely voluntary and freedom to withdraw from the study at any time during the progress of the study would be accepted.

At each research site researchers took the respondents into one large room where they explained the purpose of the visit again to those who had agreed to participate. In addition, drug misuse which was a key concept in this study was described so that the respondents would understand it clearly and thus be able to 
answer the questions that were posed more knowledgeably. The randomly selected participants were told to feel free to ask any questions which they felt were necessary. The respondents were given at least 30 minutes for the process. The completion of the questionnaires was within 30 minutes. All the 88 questionnaires were returned.

\section{Data Analysis strategy}

The data was analysed using the descriptive statistics where responses were presented in tables showing frequencies and corresponding percentages. The researchersalso usedthe chi-square test of association in the Minitaboutputpackage to compare the candidates' views on drug misuse association basing on type of school and gender. The chi-square test was used to compare if responses for girls/boyscandidates at coeducational school and girl/boys candidates at a single sex boarding high school was the same or different. The chi-square test was also used to find out whether responses are uniform in all the schools under study. In order to use the chi-square test of association some hypothesis were formulated. The first set of hypothesis was to find if there was association of responses between males and female candidates on drugs preferences. The following hypotheses were made:

Null: There is no association in the responses of male and female candidates in the preferences of drugs.

Alternative: There is an association in the responses of male and female candidates in the preferences of drugs. The second first set of hypothesis was to find if there was association of responses between candidates in private and government boarding schools in the preferences of drugs. The following hypotheses were made:

Null: There is no association in the responses by candidates in private and government boarding schools in the preferences of drugs.

Alternative: There is an association in the responses by candidates in private and government boarding schools in the preferences of drugs.

The thirdset of hypothesis was to find out if there was association of responses between female candidates at government females only boarding high school and those at private co-educational boarding high school on the top four most misused drugs. The following hypotheses were made:

Null: There is no association in the responses of female candidates at government females only boarding high school and those at church run co-educational boarding high school on the use oftop four most misused drugs. Alternative: There is an association in the responses of female candidates at government females only boarding high school and those at church run co-educational boarding high school on the top four most misused drugs.

The fourthset of hypothesis was to find out if there was association of responses between male candidates at government males only boarding high school and those at church run co-educational boarding high school on the top four most misused drugs. The following hypotheses were made:

Null: There is no association in the responses of male candidates at government males only boarding high school and those at church run co-educational boarding high school on the use of top four most misused drugs. Alternative: There is an association in the responses of male candidates at government males only boarding high school and those at church run co-educational boarding high school on the top four most misused of drugs.

\section{Results AND Discussion}

The bio-data profile provides characteristics of the candidates who participated in the study.

\begin{tabular}{|c|c|c|c|c|}
\hline School & & Govt Girls Boarding & Govt Boys Boarding & Church run Co-Ed Boarding \\
\hline \multirow[t]{3}{*}{ Age } & $15-16 y r$ & 5 & 2 & 18 \\
\hline & $17-18 y r$ & 6 & 4 & 32 \\
\hline & above $18 \mathrm{yr}$ & 0 & 6 & 13 \\
\hline \multirow[t]{2}{*}{ Sex } & Male & 0 & 13 & 37 \\
\hline & Female & 11 & 0 & 27 \\
\hline \multirow[t]{2}{*}{ Level of Education } & O level & 7 & 7 & 39 \\
\hline & A-level & 4 & 6 & 25 \\
\hline \multirow[t]{2}{*}{ Religion } & Christianity & 11 & 12 & 63 \\
\hline & Islam & 0 & 1 & 1 \\
\hline \multirow[t]{2}{*}{ Parents } & Orphan & 1 & 3 & 7 \\
\hline & Has parents & 10 & 10 & 56 \\
\hline \multirow[t]{4}{*}{ Guardian } & Sister & 1 & 2 & 4 \\
\hline & Brother & 0 & 1 & 2 \\
\hline & Uncle/Aunt & 1 & 0 & 1 \\
\hline & Grandma & 1 & 1 & 0 \\
\hline
\end{tabular}

The table 1 shows that a total of 88 high schoolcandidates participated in the study. Their ages ranged from 15 years to above 18 years. Thecandidates are from government boys, girls and a church run co-educational boarding high schools. The candidates comprised of" O" and "A"-level students. The sample was composed of 
$50(57 \%)$ males and $38(43 \%)$ female candidates. $53(60 \%)$ of the candidates are doing 0-level whilst $35(40 \%)$ of them are A -level candidates. The majority $63(72 \%)$ is Christians and only 1(1\%) are Islam. The remaining $24(27 \%)$ did not disclose their religion. This implies that majority of the candidates come from a Christian background bound by the same norms and values. Eleven (13\%) of these candidates are orphans and 76(86\%) have a living parent and one $(1 \%)$ of the candidates did not disclose the status of his/her parents. Fourteen $(16 \%)$ of the candidates stay with guardians. The statistics of candidates staying with guardians show that three $(3 \%)$ are not orphans.

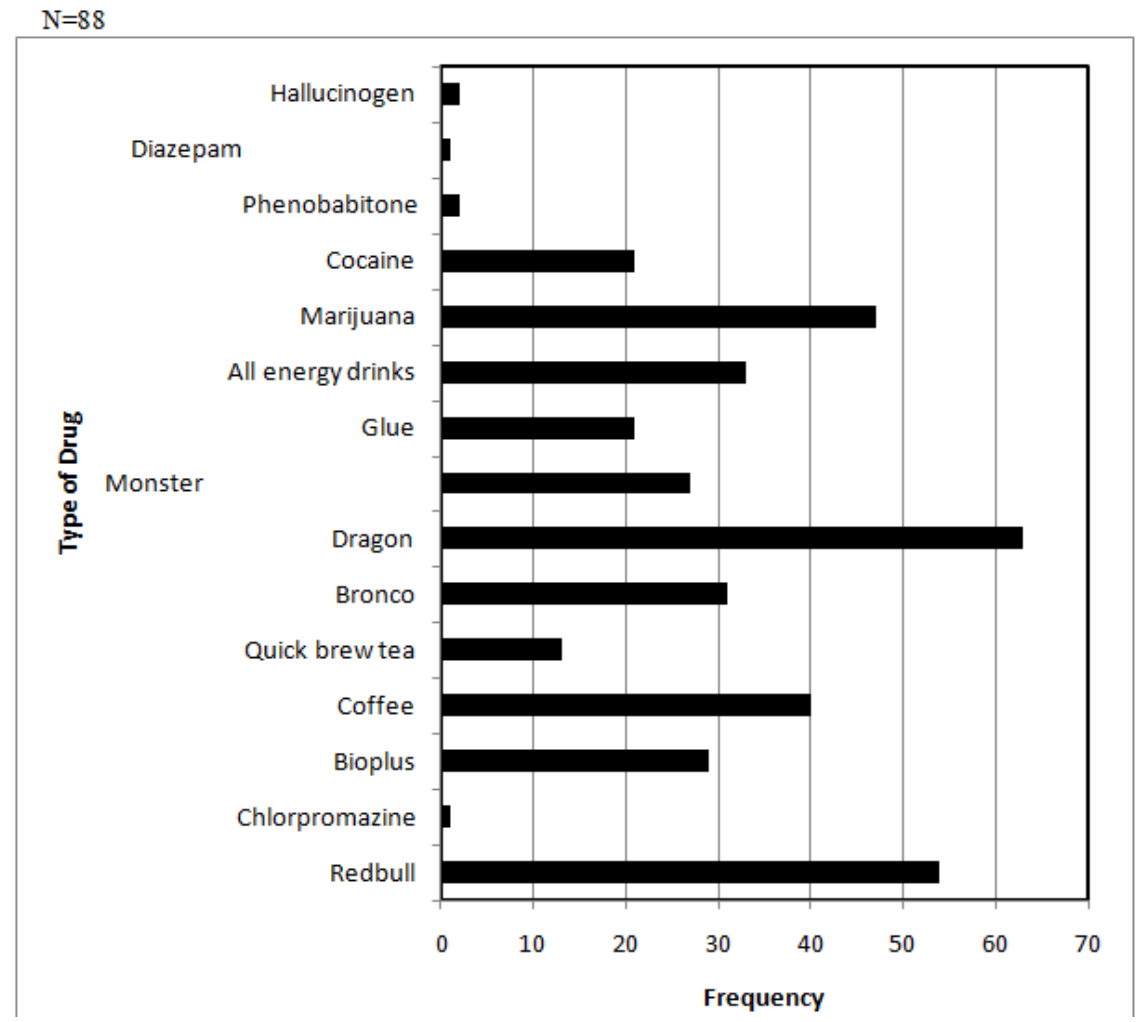

Figure 1: Drugs misused by candidates

Figure 1 shows the drugs that are mostly misused by high school ZIMSEC candidates. The results reveal that dragon is misused by 63(72\%) of the ZIMSEC candidates, seconded by red bull with 54(61\%) and Marijuana/Cannabis/ Mbanje 47(53\%). Coffee with 40(45 \%,) All energy drinks with 33 (38\%), Bronco $31(35 \%)$, Bio plus 29(33\%), Monster 27(31\%). Glue and Cocaine are also abused drugs with $21(24 \%)$ each. The other misused drugs include Zed, Quick brew, Phenobabitone, Matapi/ Kyon, Morphine, Everest, Madison, Chlorpromazine/ Maragada and Diazepam. This study results confirm Anti -Drug Abuse Association of Zimbabwe, (2015) which reported that high school students in Harare are abusing drugs such as cannabis and Broncleer. Therefore, these results confirm that drug abuse by high school students is prevalent in Mutare urban and Peri urban as well. This study results concur with Rudatsika,et,et al., (2009) who also found that marijuana and glue was being abused among school going adolescents in Harare, Zimbabwe,

This study results show that use of drugs in Zimbabwe high schools is higher compared to study by The American National Institute on Drug Abuse which came up with Drug Facts on High School and Youth Trends in 2005. The facts were on the American $8^{\text {th }}, 10^{\text {th }}$ and $12^{\text {th }}$ graders who showed a high rate of e-cigarette smoking as marijuana $20,9 \%$, cocaine $20 \%$, cough medicine $4,1 \%$ and hallucinogens $4,0 \%$. The results also concur with Harkin et,al.,(1997) in a study--- found that Cannabis was used in early adolescence with heaviest use in the 15-24 years age group which was the age group studied. The results also support Roe \& Man (2006) in their study in the U.K who found out that Marijuana/Cannabis /Mbanje was the most abused drug.

The results also show that candidate in Mutare urban and Peri urban are poly drug abusers. The study results also concur with Roe \& Man,(2006), in a National British Crime Survey 2005/6, with statistics which show that $34.9 \%$ of $16-59$ years olds had used one or more illicit drugs in their life time. This age group is the same with the respondents in this study. The study results also concur with Kasujja (2016) in Uganda who reported that students start abusing drugs as early as 11 years. The students also use similar drugs as those used by Zimbabwean high schools such as marijuana $(17,9 \%)$ and cocaine $(6,3 \%)$. However, the percentage of taking the same drugs is higher in Zimbabwe were students consume $20,9 \%$ marijuana and $20 \%$ cocaine. 


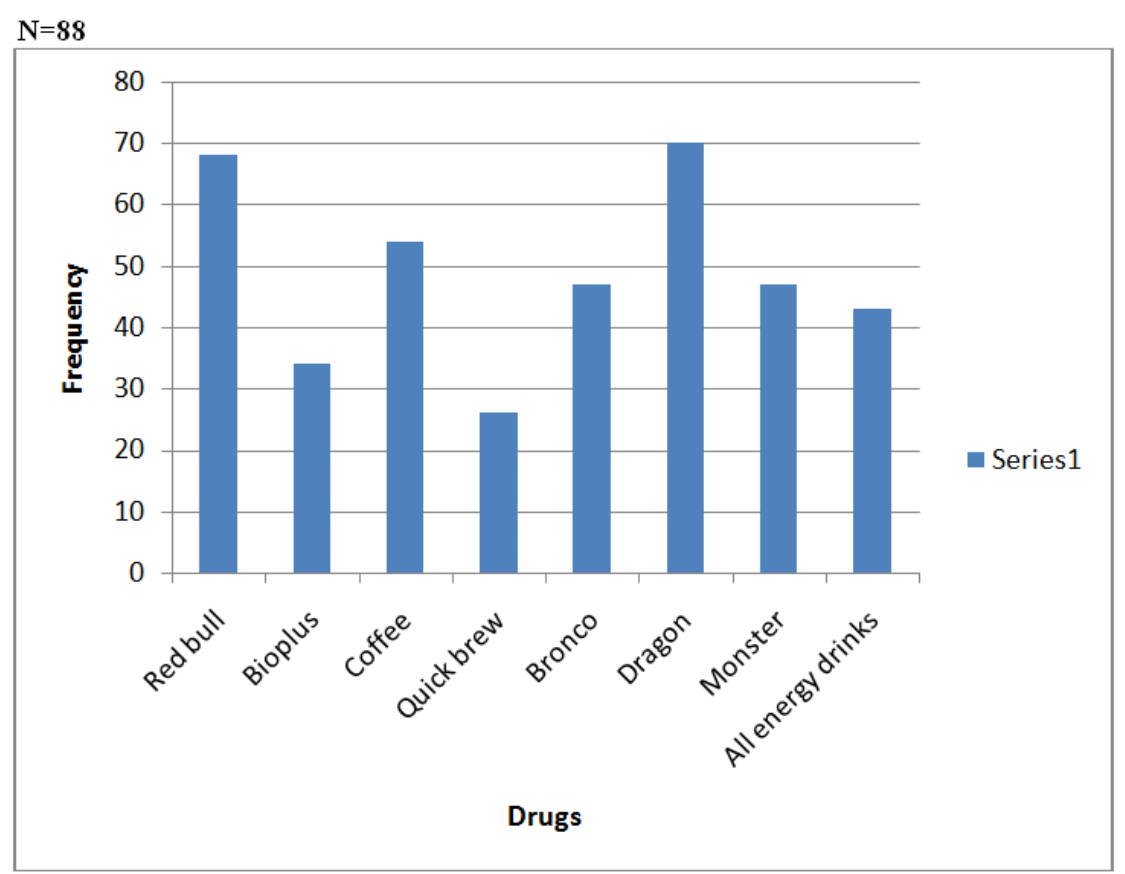

Figure2: Drugs administered orally

Figure 2 shows that the majority of the drugs are taken orally. These include Red bull, Dragon, Coffee, Monster, Bronco, All energy drinks, Bioplus and Quickbrew. The results also indicate that drugs like Glue, Marijuana, Cocaine, Phenobabitone and Diazepam are also taken orally. The poly abused drugs by high school candidate were noted to be Marijuana, Cocaine and Glue. Marijuana and Cocaine are taken via several routes which include oral, sniffing, smoking and injection. The most abused drug through several routes is Marijuana. Results indicate that $12(14 \%)$ take it orally, $9(10 \%)$ through sniffing, 48(55\%) through smoking and $4(5 \%)$ through injection. This gives us a total of 73 (84\%)of the candidates abusing it through different routes. This implies that Marijuana is easily accessed by candidates. Probably the drug is grown in the community or accessed from the neighboring country Mozambique. On the other hand Cocaine is taken by a total of $37(42 \%)$ candidates. Twenty $(23 \%)$ candidates sniff Cocaine, $5(6 \%)$ smoke it, $5(6 \%)$ take it orally and $7(8 \%)$ take it through injections. This study concurs with Roe \& Man (2006) who states that Cocaine is one of the most commonly misused illicit stimulants in the UK. Stimulant cocaine is generally sniffed in powder form, usually smoked but sometimes injected. Glue is sniffed, smoked and taken orally, whilst Phenobabitone is smoked, injected and taken orally.

\section{The frequency of taking Drugs}

The results show that $22(25 \%)$ take the drugs weekly, 38(43\%) daily, 11(13\%) twice daily and 3(3\%) three times a day. Fourteen $(16 \%)$ did not reveal the frequency of taking the drugs. These results reveal thatmajority (59\%) of the candidates misuse the drug daily. This study results concurs with the Monitoring the Future Survey (2012) found out that males in high school and colleges especially high school seniors $9 \%$ use marijuana daily. This may indicate that the drug level in the candidate's body remains high and the candidates may become addicted to the drugs.

\section{Comparison on use of drugby gender}

The first hypothesis was to find if there was association of responses between males and femalecandidates in the preferences of drugs such as dragon, red bull, marijuana and coffee. The chi-square test of association show a Pearson Chi-Square $=1.301$, Degree of Freedom $=3$ and a P-Value $=0.729$. The results show that there are no association in the preferences of drugs (dragon, red bull, marijuana and coffee) between boys and girls since a P-value $=0.729>0.05$. The difference is not significant. This means that we reject the null hypothesis: There are no differences in the responses of male and female candidates in the preferences of drugs. These results may suggest that probably the candidates collaborate when sourcing the drugs or if we turn to the African culture that men provide for the women, girls may get drug supplies from the boys at the schools. However, these results concur with the American Monitoring the Future Survey,(2012) which found out thatyounger teens girls tend to abuse drugs at the same rate as boys while the same study focusing on adolescence and young adults does not concur with this study. In the noted survey, males in high school and college and among high school seniors $9 \%$ of them use marijuana daily whilst less than, $4 \%$ females use it 
daily.Rudatsika, et al., (2009) concurs with this study that marijuana and glue are misused by high school students in Zimbabwe and males were more likely to have used marijuana or glue than females. On the other hand, Walter,(2004) in a National Survey on drugs and health found that girls surpass boys in abusing prescription drugs. Of the youths surveyed in $200414.4 \%$ of girls and $12.5 \%$ boys were reported misusing prescription drugs The second first hypothesis was to find if there was association of responses between candidates in church run and government boarding schools in the preferences of the four top most misused drugs such as dragon, red bull, marijuana and coffee. The chi-square test of association show a Pearson Chi-Square = 1.843, Degree of Freedom $=3$ and a P-Value $=0.606$.

The results show that there are no association between institutions in the intake of the four most misused drugs (dragon, red bull, marijuana and coffee) among candidates since a P-value $=0.606>0.05$. The difference is not significant. This means that we reject the null hypothesis: There are no association in the responses by high school candidates in church run and government boarding schools in the intakeof the four top most misused drugs. These results may suggest that we cannot associate the drugs misuse and type of institution, government and church run boarding school. This study results do not concur with Kasujja (2016) in a study in Uganda. Kasujja reported that drug misuse is significantly high with private high schools $31 \%$, boarding high schools $25 \%$ and day high schools $15 \%$

The third hypothesis was to find out if there was association of responses between female candidates at government females only boarding high school and those at church run co-educational boarding high school on the intake of the four most misused drugs (that is dragon, red bull, marijuana and coffee). The chi-square test of association show a Pearson Chi-Square $=4,662$ Degree of Freedom $=3$ and a P-Value $=0.198$ The results show that there is noassociation between responses of female candidate at government and those at church run boarding High schools on the intake of the four most misuseddrugs (dragon, red bull, marijuana and coffee) since a $\mathrm{P}$-value $=0.198>0.05$. The difference is not significant. This means that we reject the null hypothesis: There are no differences in the responses of female candidates at government females only boarding high school and those at church run co-educational boarding high school on the use of the top four most misused drugs. These results may suggest that we cannot associate the drugs intakeand type of institution, government and private boarding school.

The fourth hypothesis was to find out if there was association of responses between the type of drugs and controlled drugs namely Marijuana, cocaine, Broncleer/bronco and glue and sex. The chi-square test of association show a Pearson Chi-Square $=2,198$, Degree of Freedom $=3$ and a P-Value $=0.532$.The results show that there was no association between responses ofthe use of controlled drugs and sex since P-value $=0.532$ $>0.05$. The difference is not significant. This means that we reject the null hypothesis: There are no association in the responses of male and female candidates at government single sex boarding and those at church run coeducational boarding high school on the use of controlled drugs. The results suggest that sex does not matter when candidates decide to use drugs to enhance brain alertness during examination time.

\section{Conclusions}

From the findings in this study it is possible to reach several conclusions. The first is that candidatesmisuse drugs such as dragon, red bull, coffee, marijuana, bio-plus, bronco, glue, all energy drinks, and monster among others. The second is that the misuse of drugs by ' $O$ ' and ' $A$ ' level candidates is prevalent in Mutare urban and periboarding high schools in Manicaland, Zimbabwe.The third is that candidates use controlled drugs such as marijuana, cocaine and glue plus bronco. The fourth conclusion is that both boys and girls in both government and church boarding high schools take drugs even the controlled once at the same rate. The fifth is that probably high school candidates socialise or interact a great deal. These results concurwith results found elsewhere.

\section{Recommendations}

The high school candidates are involved in drug misuse in Zimbabwe.Therefore the following recommendations are made: There is need for sensitisation of drug misuse/abuse and the effects of drugs on health and the environment in the schools. Education on drug misuse should be taken seriously. At the moment the school's curriculum includes the Zimbabwe Pledge in which core values generallyare taught and most schools concentrate on the teaching of core subjects and scraping on the surface on core values such as unhu/ubuntu. Policy on control of all energy drinks which are sold in the streets and are subject to abuse should be drafted and implemented. Policy Control on use of illicit drugs should be tightened. It is also recommended that in future researchers to look at the influence of technology and media on children's and adolescent's drug abuse. 


\section{References}

[1]. Anthony, J. C., Warner, L. A., \& Kessler, R. (1994). Comparative epidemiology of dependence on tobacco, alcohol, controlled substances and inhalants: basic findings from the National Co morbiditySurvey. Experimental and Clinical Psychopharmacology.1994;2: 244-268.

[2]. Bachman, J. G., Wadsworth, K. N.,\& O’Malley, P.(1997).Smoking, drinking and drug use in young adulthood: The impacts of new freedoms and responsibilities. Mahwah, N J: Lawrence Erlbaum.

[3]. Bancroft, A., Carty, A., \& Cunning ham- Burley, S.(2002). Support for the families of drug users: A review of literature. Edinburgh; Scottish Executives Interventions Unit: 2002

[4]. Bandura, A.: Stajkovic, A.D.: and Luthans, F.(1998) Social Cognitive Theory and self- efficacy: Implications for Motivation Theory andPracticehttps://www.researchgate.net/profile/Alex_Stajkovic/publication/258995495_Social_cognitive_theory_and_selfefficacy_Implications_for_motivation_theory_and_practice/links/00b7d5299300b9f0c2000000.pdf

[5]. Compton, W. M. \& Volkow, N. D. (2006). Major increases in opiods, analgesic abuse in the United States: Concerns and strategies. Drug alcohol depends. Feb 1; 81(2): 103-7.

[6]. Dackis, C.\& O’Brien, C.(2005). Neurobiology of addiction: Treatment and Public Policy Ramifications .Nat Neurosci, Nov; 8(11): 1431-6.

[7]. Godfrey, C. Eaton, G.\& Mc Dougall, C. (2002). The Economic and social costs of class and drug use in England and Wales. Home Office Research Study p.249, London: Home Office.

[8]. Etten, V. \& Anthony, J.C. (1999). Comparative epidemiology of initial drug opportunities and transition to first use: marijuana, cocaine, hallucinogens and heroin: Drug and Alcohol Dependence 54: 117-125, 1999.

[9]. Etten,V., Neueumark, Y. D.\& Anthony, J. C. (1999). Male-female differences in the earliest stages of drug involvement. Addiction 94(9):1413-1419. https://www.therecoveryvillage.com/drug-addiction/study-between-genders/.

[10]. Frischer., Crome,I.,\& Macleod,J. (2005). Predictive factors for illicit drug use among young people: a literature review. Home Office On line Report 05/ 07. London: Home Office

[11]. Gossop,M., Marsden,J., Stewart,D. \& Treacy,S.(2000). Routes of drug administration and multiple drug misuse: Regional variations among clients seeking treatment at programmes throughout England.Pubmed.gov U.S National Library of Medicine National Institute of Health.

[12]. Harkin, A. M., Anderson, P., \&Goos, C.(1997). Smoking, drinking and drug taking in the European Region Copenhagen: WHO Regional Office for Europe.

[13]. Judd,A. Hickman, M. \&Jones, S.(2005). Incidence of hepatitis C virus and HIV among new injecting drug users in London: Prospective Cohort Study. British Medical Journal 2005; 330: 24-25

[14]. Kumpfer, K. L.\& Bluth, B (2004). Parent/ Child transactional processes predictive of resilience or vulnerability to 'substance abuse disorder' substance use and misuse 39: 671-698.

[15]. Kasujja, C. (2016) Alcohol, cigarettes most abused drugs in schools. http://www.newvision.co.ug/newvision/news/1420812studyalcohol-kuber-cigarettes-abuseddrugs-schools.

[16]. Kuria, M.W. (1996). Drug Abuse among urban as compared to rural secondary schools students in Kenya: a short communication.PubMed-Indexed for MEDLINE.

[17]. Munn, P.\& Drever, E (1999). Using Questionnaires in Small Scale Research: A Teacher's Guide Scottish Council for Research in Education, Edinburgh.

[18]. National Institute on Drug abuse (2000). Gender differences in prevalence of drug abuse traced to opportunities to use by Patrick Zickler: NIDA NOTES staff writer: Volume 15 Number4, September, 2000

[19]. Petry, N. M., Tedford, J. \&Austin, M.(2004). Prize reinforcement contingency management for treating cocaine users: How low can we go, and with whom? Addiction 99: 349-360.

[20]. Regier, D.A., Farmer, M. E., Rae, D.S., Locke, B. Z., Keith, S. J., Judd, L. L., \& Goodwin, F. K.(1990). Co morbidity of mental disorders with alcohol and other drug abuse: Results from the epidemiologic catchment area (ECA) study. November 21; 264 (19): 2511-8.

[21]. Roe, S. \& Man, L.(2005). Drug misuse declared. Findings from the British Crime Survey 2005/ 06-England and Wales, London: Home Office.

[22]. Rudatsika, E., Maposa, D., Mukandavire Z, Muula AS and Siziva S (2009) .The prevalence and predictors of illicit drug use among school-going adolescents in Harare, Zimbabwe.

[23]. The Patriot Reporter (2015). Alarming levels of drug abuse in schools, March 19, 2015, file://G:/Alarming\%20of\%20drug\%20abuse\%20in\%20schools\%20 \%20Celebrating\%20Being\%20Zimbabwe.

[24]. Tichapondwa, M. (2013).Preparing your dissertation at a distance: A research guide.

[25]. Vancouver: Virtual University for Small States of the Commonwealth (VUSSC) and the

[26]. Southern African Development Community (SADC), Centre for Distance Education (CDE) - (SADC-CDE).

[27]. Volkow, N. Li, T. K. (2005). The neuroscience of addiction: Nature Neuroscience. 8: 1429-1430.

[28]. Walter, J. (2006).Girls using drug, alcohol more than boys.http://www.nbcnews.com/id/11259729/ns/health-addictions/t/girls-usingdrugs-alcohol-more-boys.

[29]. Ward, J., Henderson, Z., \& Pearson, G. (2003). One problem among many: Drug use among care leavers in transition to independent living, London: Home Office. 